EIXO TEMÁTICO:

( ) Bacias Hidrográficas, Planejamento e Gestão dos Recursos Hídricos

( ) Biodiversidade e Unidades de Conservação

( ) Campo, Agronegócio e as Práticas Sustentáveis

( ) Cidade, Arquitetura e Sustentabilidade

( ) Educação Ambiental

( ) Geotecnologias Aplicadas à Análise Ambiental

( ) Gestão dos Resíduos Sólidos

( ) Gestão e Preservação do Patrimônio Arquitetônico, Cultural e Paisagístico

( $\mathrm{x}$ ) Mudanças Climáticas

( ) Novas Tecnologias Sustentáveis

( ) Paisagem, Ecologia Urbana e o Planejamento Ambiental

( ) Saúde, Saneamento e Ambiente

( ) Turismo e o Desenvolvimento Local

\title{
A variabilidade das precipitações e os impactos dos Processos erosivos na área urbana de Rancharia (SP)
}

The variability of rainfall and the impacts of Erosion in Rancharia (SP)

La variabilidad de las precipitaciones y los impactos

De erosión urbana en área urbana de Rancharia (SP)

\author{
Alyson Bueno Francisco \\ Doutor em Geografia \\ alysonbueno@gmail.com
}


Este artigo apresenta uma análise das concentrações das precipitações em anos chuvosos e a variabilidade sazonal da erosividade da chuva em Rancharia (SP), relacionando aos impactos provocados à drenagem urbana e evento de erosão remontante no ano de 2015. Na estimativa da erosividade das chuvas, para o meses de janeiro e dezembro em Rancharia, foram constatados $1.500 \mathrm{MJ} . \mathrm{mm} / \mathrm{ha}$.h nos anos chuvosos. São apresentados os resultados da metodologia empírica de Thornthwaite (1948) nos anos de 1972, 1983, 2009 e 2015, sendo este último período marcado pelo desenvolvimento de erosão remontante em Rancharia (SP). Os índices de excedente hídrico são importantes na aplicação em Climatologia para as análises relacionadas ao escoamento superficial em áreas urbanas e planejamento da drenagem urbano na escala municipal.

PALAVRAS-CHAVE: drenagem urbana; erosividade; ENOS.

\section{ABSTRACT}

This article presents an analysis of the concentration of rainfall in rainy years and seasonal variability of rainfall erosion in Rancharia (SP), relating to the urban drainage impacts and mountain erosion event in the year 2015. In the estimation of the erosion of the rains, for the months of January and December in Rancharia, 1,500 had been evidenced in rainy years MJ.mm/ha.h. Are presented the results of the empirical methodology of Thornthwaite (1948) in 1972, 1983, 2009 and 2015, being this last period marked by mountain erosion development in Rancharia. Surplus water rates are important in application in Climatology for the analyses related to runoff in urban areas and urban drainage planning in municipal scale.

KEY-WORDS: urban drainage; rainfall erosion; ENSO.

\section{RESUMEN}

Este artículo presenta un análisis de la concentración de precipitaciones en años lluviosos y variabilidad estacional de la erosión de la lluvia en Rancharia (SP), relativos a los impactos de drenaje urbano y evento de erosión de la cárcava en el año 2015. En la estimación de la erosión de las lluvias durante los meses de enero y diciembre en Ranchi, 1.500 había sido evidenciado en años lluviosos MJ.mm/ha.h. Se presentan los resultados de la metodología empírica de Thornthwaite (1948) en 1972, 1983, 2009 y el 2015, siendo esta última época marcada por el desarrollo de la erosión de la cárcava en Rancharia. Sobra las tarifas de agua son importantes en aplicaciones en climatología para los análisis relacionados con el escurrimiento en zonas urbanas y drenaje urbano planificación en escala municipal.

PALABRAS-LLAVE: drenaje urbano; erosion de la lluvia; ENOS 


\section{INTRODUÇÃO}

Os fenômenos atmosféricos desde a Grécia Antiga foram analisados para a compreensão de suas dinâmicas na natureza pelo avanço do conhecimento científico. O resgate das discussões da filosofia da ciência é importante para a análise dos métodos empregados pelos pesquisadores sobre os estudos meteorológicos e climáticos.

A análise dos fenômenos da natureza incluindo o tempo meteorológico, apresentada por Aristóteles (384 - 322 a.C.), era dependente da percepção (sensação) e marcada pela ausência de dados empíricos, como apresenta:

[...] a sensação gera-se ao mesmo tempo que o sujeito sensível (que sente), pois que a sensação nasce com o ser animado, mas o sujeito sensível não é anterior nem ao ser animado nem à sensação, dado que objetos como fogo, água, e outros elementos da natureza, a partir dos quais o ser animado se compõe, já existiam anteriormente ao ser animado e à sensação (ARISTÓTELES, 1985, p. 75).

O monitoramento dos fenômenos atmosféricos pelos avanços tecnológicos no campo da Meteorologia garante o desenvolvimento de pesquisas geográficas na escala local, sendo esta escala utilizada nos últimos anos com mais frequência pelos estudos sobre o clima urbano (MENDONÇA; MONTEIRO, 2003).

As mudanças no uso da terra pela urbanização das vertentes geram modificações na dinâmica dos escoamentos superficiais, sendo preocupantes os impactos causados pelas velocidades das águas pluviais em áreas urbanizadas com declividades acentuadas. A urbanização implica a instalação de sistemas de drenagem urbana para o direcionamento das águas pluviais pelos lotes urbanos, logradouros até os cursos d'água receptores. No entender de Tucci (2005), a drenagem urbana é formada por um conjunto de medidas infraestruturais que visam amenizar os impactos aos solos causados pela impermeabilização e urbanização em microbacias hidrográficas, e ressalva:

[...] como em drenagem urbana o impacto da urbanização é transferido para jusante, quem produz o impacto geralmente não é o mesmo que o sofre o impacto. Portanto, para um disciplinamento do problema é necessário a interferência da ação pública através da regulamentação e do planejamento (TUCCI, 2005, p. 17).

A cidade de Rancharia (SP) apresenta um histórico de problemas relacionados ao desenvolvimento de boçorocas conforme estudos apresentados por Oliveira (1994) e Francisco (2017). Nos anos de 1997 e 2015 ocorreram episódios de precipitações concentradas e o desenvolvimento da erosão remontante na boçoroca do Córrego do Grito, comprometendo o sistema de macrodrenagem urbana (FRANCISCO, 2017).

O clima de Rancharia (SP), localizada na latitude de 22015'S é do tipo tropical continental (Cfa) com uma precipitação anual média de $1.328 \mathrm{~mm}$, sendo a média de $512 \mathrm{~mm}$ de precipitação 
pluvial durante o verão e a média de $149 \mathrm{~mm}$ de precipitação pluvial durante o inverno (BOIN, 2000).

Francisco (2017), a partir de uma análise dos índices pluviométricos numa série histórica entre os anos de 1945 e 2003, constatou uma pluviosidade média anual de aproximadamente 1.300 $\mathrm{mm}$, com casos de anos de pluviosidades acumuladas acima de $1.500 \mathrm{~mm}$.

Sudo (2000) considera que os processos erosivos em áreas com solos vulneráveis podem ser desencadeados durante precipitações concentradas, principalmente em regiões de clima tropical marcadas pela sazonalidade anual.

Diante destas condições de sazonalidade climática pela concentração das precipitações pluviais no verão e o risco de desenvolvimento de erosão remontante nas boçorocas durante anos chuvosos, neste artigo serão analisados os históricos de precipitação pluvial entre 1945 e 2016, com o intuito de analisar esta dinâmica através de histogramas gerados dos dados primários de um posto pluviométrico.

\section{PROCEDIMENTOS METODOLÓGICOS}

Para a realização dos cálculos de erosividade da chuva foram adotados como base os índices pluviométricos do posto do Departamento de Águas e Energia Elétrica (D7-065) ao apresentar dados entre 1942 e 2014. No aplicativo Excel os dados de precipitação mensal foram organizados em tabela para serem obtidos os valores das médias e desvio padrão mensais. Para identificar os anos chuvosos, anos-padrão e anos secos foram adotou-se as seguintes expressões:

Anos chuvosos: valor $>=$ média anual $+1,5$. desvio padrão

Anos-padrão: valor $<=>$ média anual $+0,5$. desvio padrão

Anos secos: valor $<=$ média anual $-1,5$. desvio padrão

No cálculo do índice de erosividade das chuvas (EI30) foram adotadas as expressões citadas por Tommaselli; Freire; Carvalho (1999):

$$
\mathrm{EI} 30=\mathrm{arc} b
$$

onde: a coeficiente de regressão correspondente a 111,68

b coeficiente de regressão correspondente a 0,714

$$
r c=p^{2} / P
$$

onde: $\mathrm{p}$ é a precipitação média mensal $(\mathrm{mm})$

$P$ é a precipitação média anual $(\mathrm{mm})$ 
Para a geração dos histogramas de balanço hídrico, foram utilizados os índices pluviométricos do posto do Departamento de Águas e Energia Elétrica (D7-036) localizado no município de Rancharia-SP (22 $14^{\circ} 09^{\prime \prime} S$ e $\left.50^{\circ} 53^{\prime} 20^{\prime \prime} \mathrm{W}\right)$.

Tarifa (1970) apresenta o método de Thornthwaite, que se baseou em equações empíricas para estimar a evapotranspiração potencial (evapotranspiração num terreno totalmente vegetado) conforme as latitudes, cujo solo comporta-se como um reservatório da água da chuva que é influenciado pelas perdas pela evapotranspiração e saídas pelo excedente hídrico. Os cálculos dos índices de evapotranspiração potencial (ETP), evapotranspiração real (ETR), déficit hídrico (DEF) e excedente hídrico (EXC) foram obtidos numa planilha do aplicativo Microsoft Excel disponibilizada pela Escola Superior de Agricultura Luiz de Queiroz.

\section{RESULTADOS E DISCUSSÃO}

A partir de índices pluviométricos do posto do DAEE (D7-065) foram estimados os índices de erosividade da chuva para o município de Rancharia.

Para os anos chuvosos, a erosividade da chuva foi estimada em $9.088 \mathrm{MJ} . \mathrm{mm} / \mathrm{ha}$.h.ano $\mathrm{Em}$ anos-padrão a erosividade da chuva foi estimada em $7.129 \mathrm{MJ} . \mathrm{mm} / \mathrm{ha}$.h.ano, e em anos secos a erosividade em Rancharia foi estimada em 5.665 MJ.mm/ha.h.ano.

A figura 1 mostra que a erosividade da chuva para o meses de janeiro e dezembro ultrapassam $1.500 \mathrm{MJ} . \mathrm{mm} / \mathrm{ha}$.h nos anos chuvosos. Em relação aos anos-padrão, os índices de erosividade ultrapassam $1.000 \mathrm{MJ} . \mathrm{mm} / \mathrm{ha}$.h nos meses de fevereiro e dezembro.

A figura 1 apresenta algumas exceções como nos meses de fevereiro, abril e outubro quando os anos secos apresentam índices de erosividade maiores do que em anos-padrão. No caso do mês de fevereiro, apresenta-se como um mês chuvoso em anos secos e com erosividade que ultrapassa $1.200 \mathrm{MJ} . \mathrm{mm} / \mathrm{ha} \cdot \mathrm{h}$ em anos secos. 
Figura 01 - Erosividades mensais em anos chuvosos, anos-padrão e anos secos em Rancharia (SP)

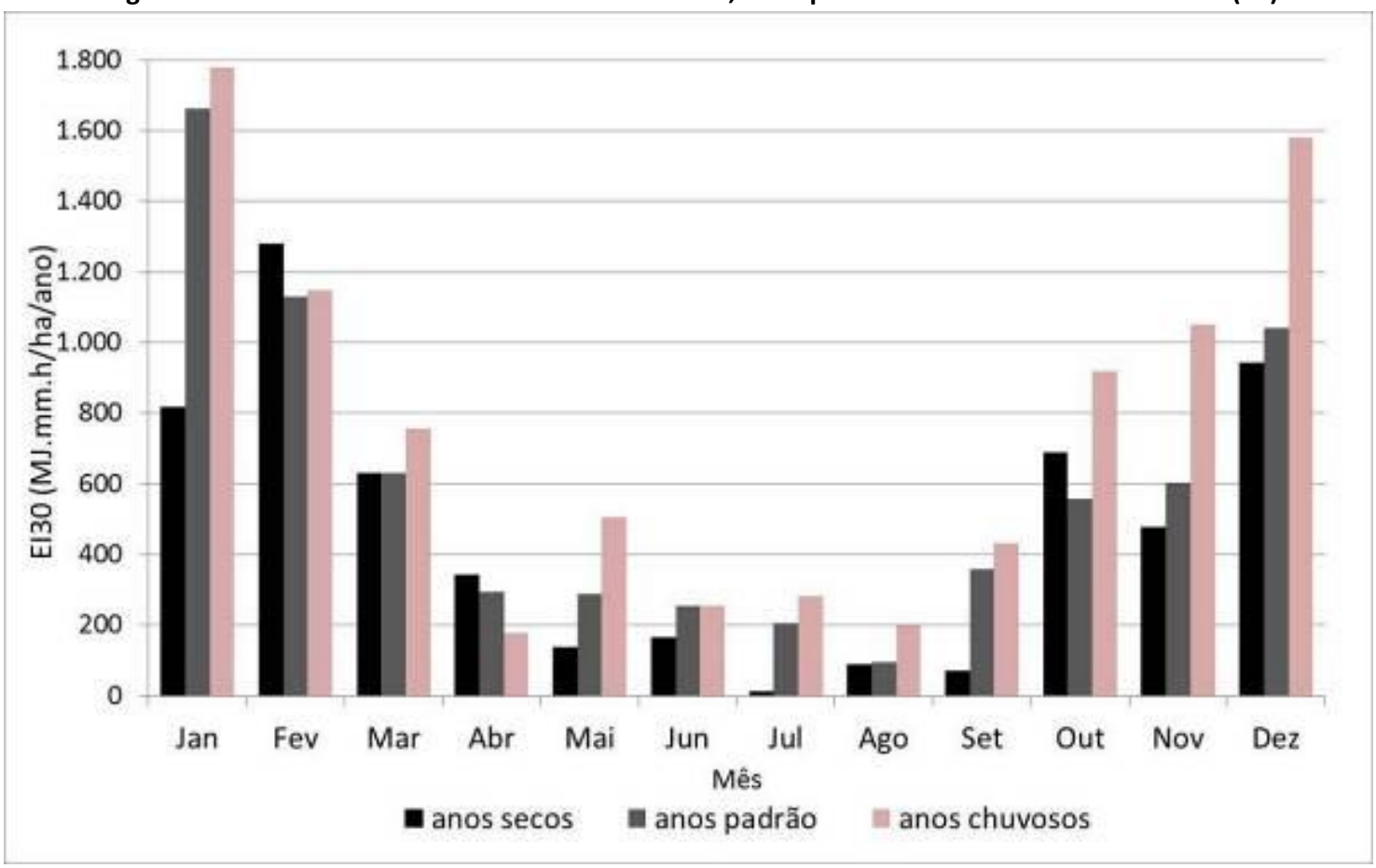

Fonte: Francisco (2017, p. 98).

Além do excedente hídrico constatado pela série histórica dos meses de verão (dezembro a março), pode-se considerar a intensidade da chuva na formação dos escoamentos superficiais captados pela macrodrenagem urbana.

Devido a análise dos impactos das precipitações concentradas na drenagem urbana neste artigo, são analisados os excedentes hídricos durante os anos chuvosos de 1972, 1983, 2009 e 2015. A tabela 01 mostra os totais pluviométricos anuais e os excedentes hídricos dos respectivos anos analisados.

\begin{tabular}{cccccc}
\multicolumn{7}{c}{ Tabela 1 - Índices do balanço hídrico de Thornthwaite para Rancharia (SP) } \\
\hline Ano & ETP & ETR & P & EXC & \% EXC / P \\
\hline 1972 & 321,89 & 321,39 & 1858,6 & 1538,8 & 82,80 \\
1983 & 321,89 & 321,39 & 1904,6 & 1595,2 & 83,60 \\
2009 & 321,89 & 321,39 & 1806,2 & 1484,3 & 82,18 \\
2015 & 321,89 & 321,39 & 2314,4 & 1993,2 & 86,12
\end{tabular}

Elaboração: Francisco, A. B. (2018)

ETP: evaporação potencial

EXC: excedente hídrico \%
ETR: evaporação real

P: precipitação pluvial

Durante o ano de 1972 ocorreu uma influência do fenômeno El Niño (Oscilação Sul) de forte intensidade, com um total de pluviosidade anual de $1.858 \mathrm{~mm}$, excedente hídrico anual de 
$1.538,8 \mathrm{~mm}$ correspondendo a uma relação de $82,8 \%$ do total de precipitação anual. A figura 02 mostra o histograma de balanço hídrico de 1972 com dados de Rancharia (SP).

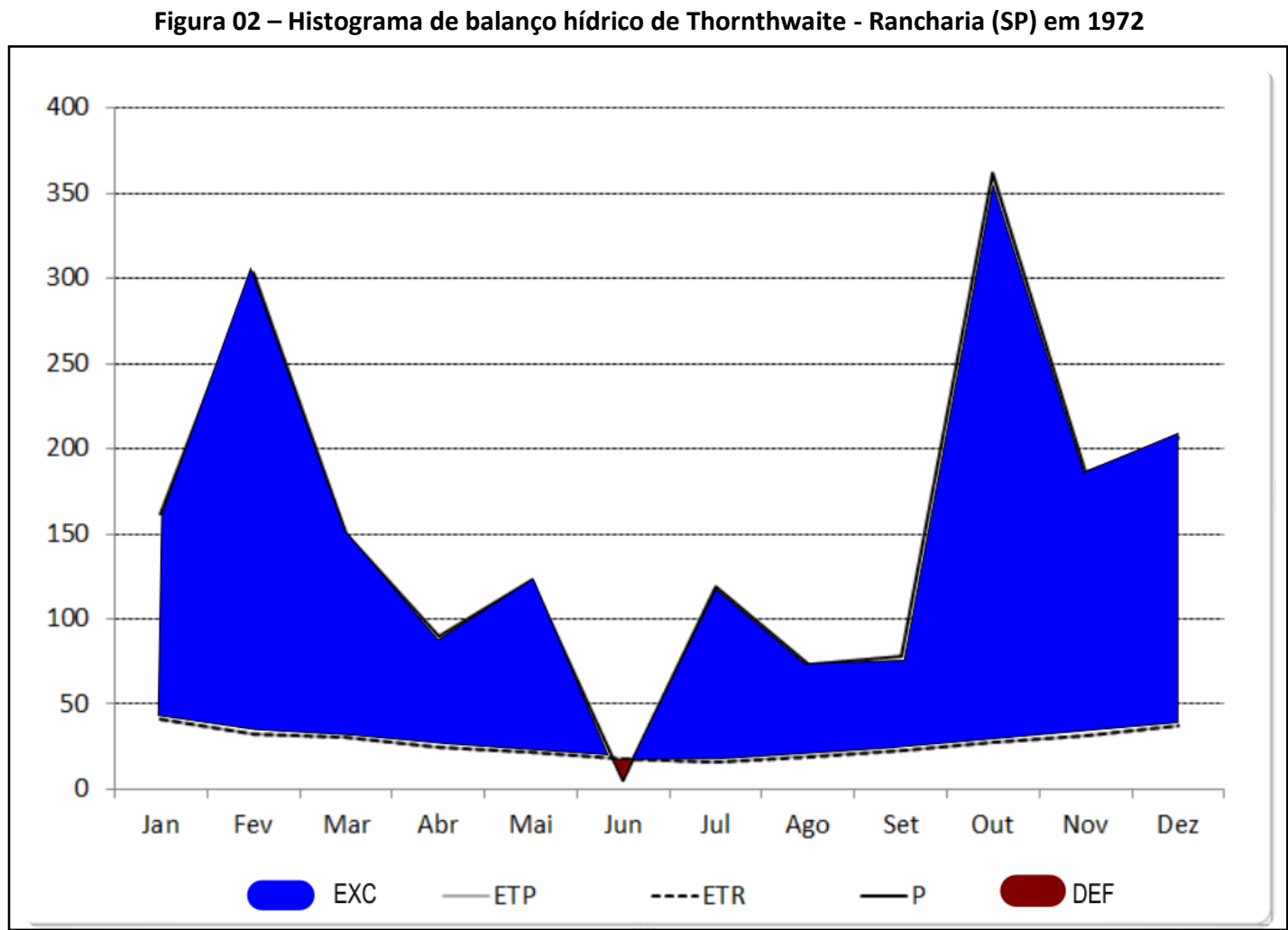

Elaboração: Francisco, A. B. (2018).

O ano de 1983 possui aspectos semelhantes ao de 1972 sobre o volume anual de precipitação e excedente hídrico com valores um pouco superiores, sendo também um ano de atuação do fenômeno El Niño (Oscilação Sul) de forte intensidade.

A figura 03 mostra o histograma do balanço hídrico com destaque para o excedente hídrico no ano de 1983 em Rancharia (SP). 
Figura 03 - Histograma de balanço hídrico de Thornthwaite - Rancharia (SP) em 1983

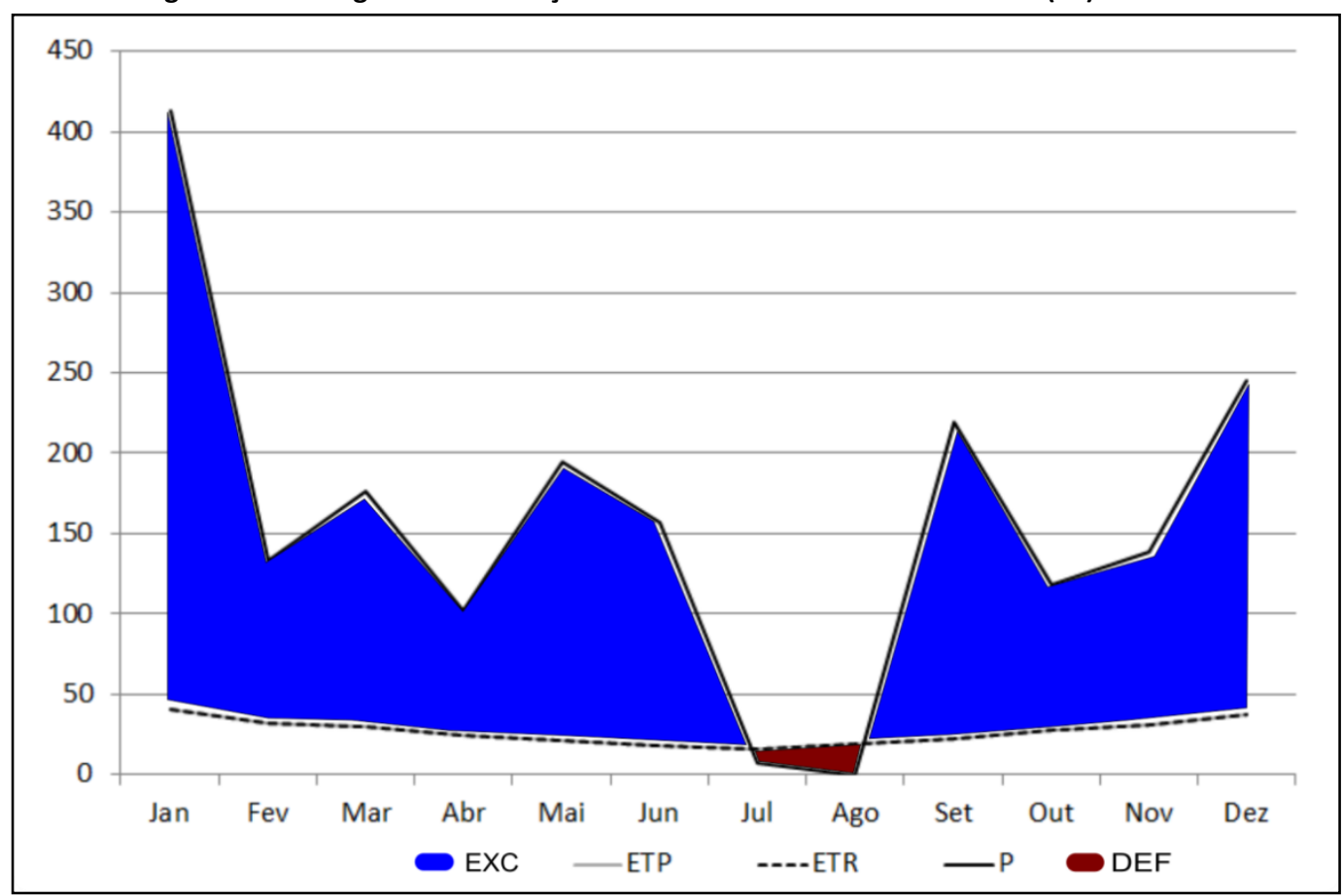

Elaboração: Francisco, A. B. (2018)

Durante o ano de 2009, com ocorrência do fenômeno ENOS de intensidade moderada, ocorreram precipitações volumosas no mês de janeiro que atingiram um total de $432 \mathrm{~mm}$ em Rancharia (SP). O histograma da figura 04 mostra destaca o excedente hídrico ocorrido no ano de 2009. 
Figura 04 - Histograma de balanço hídrico de Thornthwaite - Rancharia (SP) em 2009

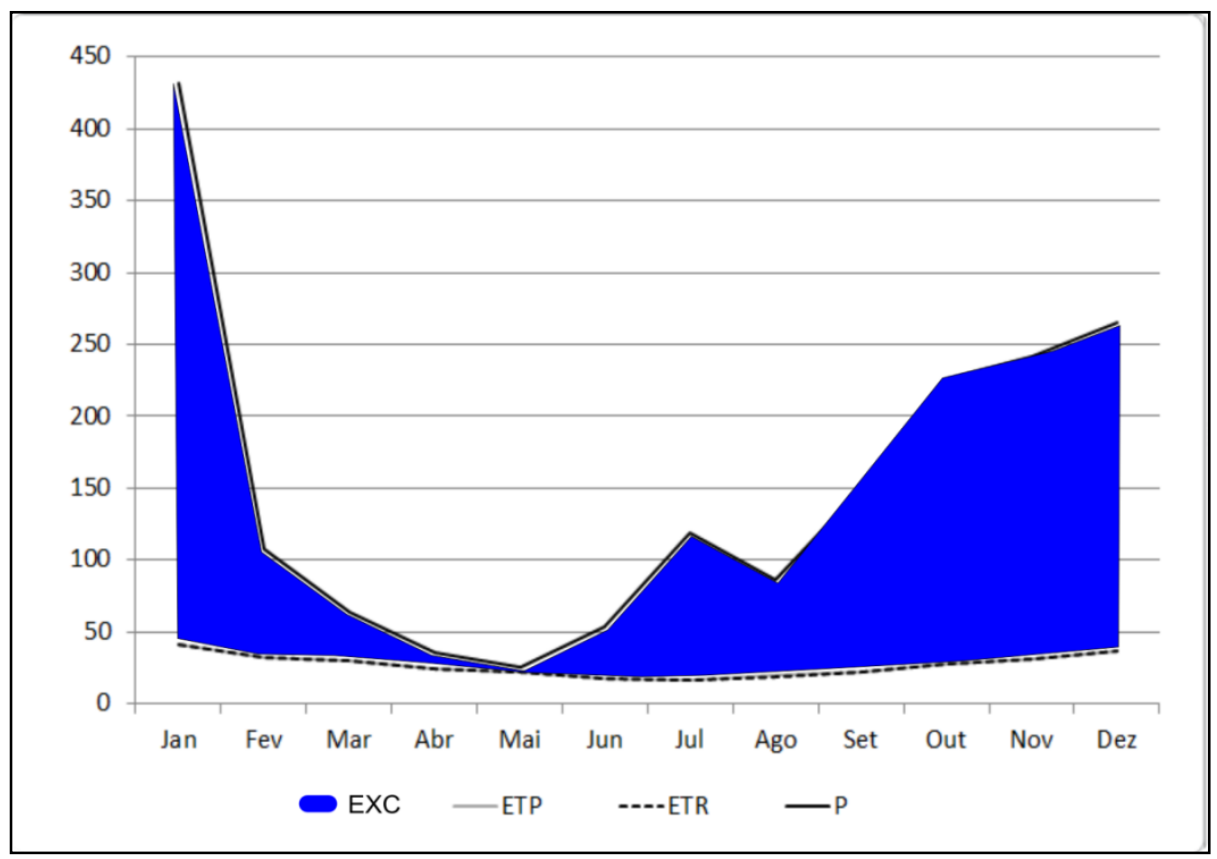

O ano de 2015 apresentou um excedente hídrico considerável no primeiro semestre como apresenta o histograma da figura 05.

Figura 05 - Histograma de balanço hídrico de Thornthwaite - Rancharia (SP) em 2015

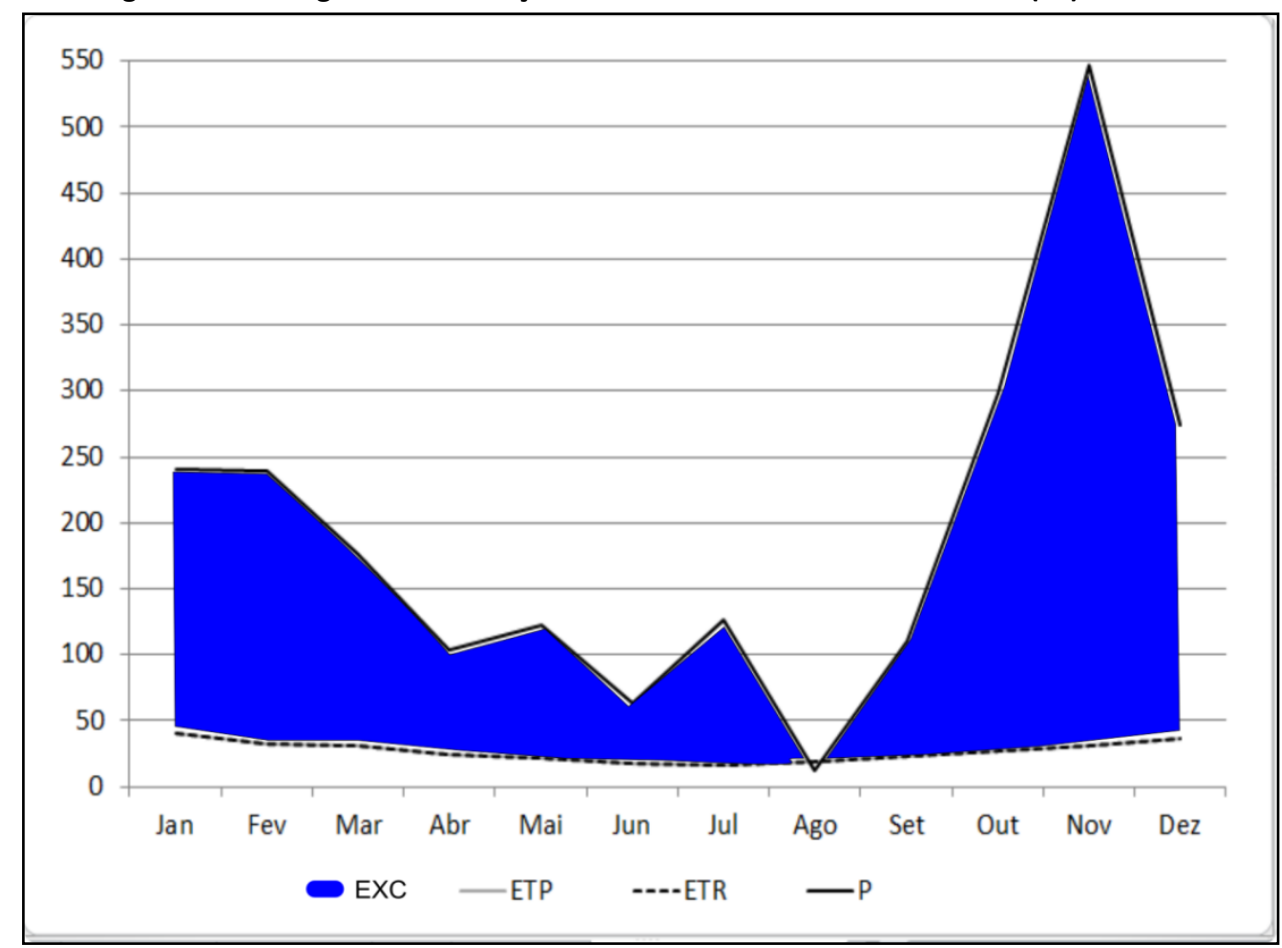

A forte intensidade do fenômeno El Niño (Oscilação Sul) também foi presente no ano de 2015 com um excedente hídrico de $888 \mathrm{~mm}$ entre os meses de janeiro e julho, provocando o 
aumento da vazão da bacia urbana do Córrego do Grito em Rancharia (SP) e o desenvolvimento de erosão remontante, como apresenta o evento da figura 06.

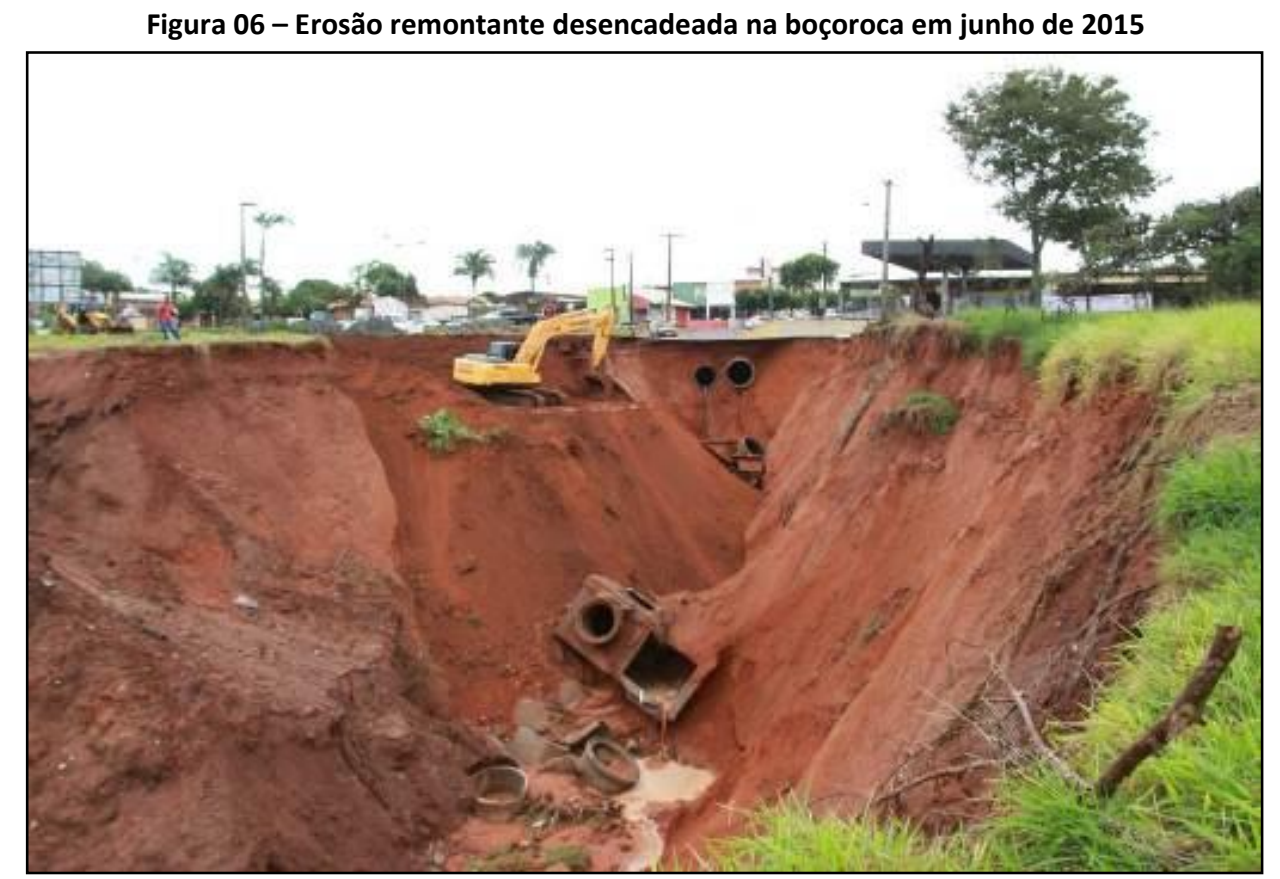

Fonte: Francisco (2017, p. 136).

No ano de 2015 o percentual de excedente hídrico em relação ao total de precipitação anual foi de $86 \%$, representando uma quantidade relevante de escoamento superficial mesmo em áreas rurais com a presença de vegetação. Numa área urbana, como foi mencionado na introdução, o escoamento superficial é mais relevante devida impermeabilização da maior parte da superfície do solo.

\section{CONSIDERAÇÕES FINAIS}

A análise do histórico das precipitações pluviais é importante para considerar a variabilidade climática com a presença de anos chuvosos e relacionados ao fenômeno ENOS, sendo um aspecto sobre a dinâmica do clima que afeta na escala local das pequenas cidades, tendo a erosão urbana em Rancharia (SP) como exemplo.

O excedente hídrico obtido com base no modelo estatístico de Thornthwaite considera os aspectos geohistogramas de latitude e utilizam dados empíricos de precipitação, adquiridos durante décadas nos postos pluviométricos, sendo um exemplo da necessidade de coleta de dados para melhor compreensão dos fenômenos naturais.

A variabilidade das chuvas provocada pelo fenômeno ENOS não é a causa da intensidade acelerada dos processos erosivos, visto que as formas de uso da terra influenciam diretamente na dinâmica de escoamento superficial em relação à infiltração das águas pluviais, sendo esta variabilidade das chuvas apenas uma "válvula de escape" para o desencadeamento da erosão remontante. 
Diante do cenário futuro de variabilidade climática, com a possibilidade de anos chuvosos em períodos concentrados, são necessárias políticas públicas que considerem a importância do conhecimento geohistograma na elaboração de planos diretores de uso do solo e drenagem urbana para evitar maiores danos à infraestrutura e impactos aos recursos hídricos.

\section{REFERÊNCIAS BIBLIOGRÁFICAS}

ARISTÓTELES. Organon. Lisboa: Guimarães Editores, 1985, tradução de Pinharanda Gomes.

BOIN, M. N. Chuvas e erosões no Oeste Paulista: uma análise climatológica aplicada. Tese (Doutorado em Geociências e Meio Ambiente), Universidade Estadual Paulista, Rio Claro, 2000, 281f.

FRANCISCO, A. B. A erosão periurbana em Rancharia-SP: a análise espaço-temporal e as propostas de recuperação da boçoroca do Córrego do Grito. Tese (Doutorado em Geografia), Faculdade de Ciências e Tecnologia, Universidade Estadual Paulista, 2017, 201f.

MENDONÇA, F.; MONTEIRO, C. A. F. Clima urbano. São Paulo: Contexto, 2003.

OLIVEIRA, A. M. S. Depósitos tecnogênicos e assoreamento de reservatórios: exemplo do Reservatório de Capivara, Rio Paranapanema, SP/PR. Tese (Doutorado em Geografia Física), Universidade de São Paulo, Faculdade de Filosofia, Letras e Ciências Humanas, 1994, 211 f.

SUDO, H. Processos erosivos e variabilidade climática. In: SANT'ANNA NETO, J. L. (org.) Variabilidade e mudanças climáticas: implicações ambientais e socioeconômicas. Maringá: Editora da UEM, p. 121-146, 2000.

TARIFA, J. R. Estudo preliminar das possibilidades agrícolas da região de Presidente Prudente segundo o balanço hídrico de Thornthwaite (1948-1995). Boletim Geográfico, n. 217, p. 34-45, 1970.

TUCCI, C. E. M. Gestão de águas pluviais urbanas. Brasília: Ministério das Cidades, 2005. 